\title{
Recruiting Students Into Optics
}

\author{
John Walkup
}

John F. Walkup, "Recruiting Students Into Optics," Proc. SPIE 0978, 1988 Intl Conf on Education in Optics, (27 April 1989); doi: 10.1117/12.948603

Event: 32nd Annual International Technical Symposium on Optical and Optoelectronic Applied Science and Engineering, 1988, San Diego, CA, United States 


\title{
Recruiting Students Into Optics
}

\author{
John F. Walkup \\ Texas Tech University, Department of Electrical Engineering \\ Lubbock, Texas 79409-4439
}

\begin{abstract}
$\underline{\text { ABSTRACT }}$
A critical issue in optics education is the recruiting of sufficient numbers of students, at both undergraduate and graduate levels, to meet the growing demand for graduates. This paper explores the problem and suggests some possible approaches for more effective recruiting.
\end{abstract}

\section{INTRODUCTION}

As the title of this paper would suggest, a continuing critical issue in optics education is how to recruit students into optics-oriented curricula in sufficient numbers to meet the rapidly growing demand. This is of particular interest when we recognize that many scientists, engineers, and educators working in optics admit that they got into the field "almost by accident" (and some would delete the "almost"). While prospective B.S., M.S. and Ph.D. students are becoming more aware of the attractiveness of optics as a career field, they may often not be aware of the various educational paths to an optics career and where they can pursue these paths. Thus they may be wondering "Is it physics, engineering, or what?"

Designated centers such as the University of Rochester's Institute of Optics, and the University of Arizona's Optical Sciences Center have some clear "visibility" advantages in recruiting by being more easily identified as places where a student can study optics. On the other hand the vast majority of recruiting of students into optics-related programs will most likely continue to be in traditionally non-optics curricula such as physics, electrical engineering and mechanical engineering. Thus the recruiting problem has many facets and its solution must also have many facets.

This paper will deal with some of the things being done to recruit B.S. and M.S./Ph.D. students into optics courses and degree programs but is, by no means, an exhaustive treatment of the subject. Rather I hope it will stimulate all of us to greater cooperation in the effort to meet the demand for more graduates with an understanding of optics. Due to the fact that the undergraduate and graduate recruiting problems are different, I will treat them in separate sections starting with undergraduate (B.S. level) recruiting.

\section{RECRUITING AT THE UNDERGRDUATE (B.S.) LEVEL}

At this level one can further subdivide the recruiting problem into the pre-college and college issues.

\subsection{Pre-college recruiting}

It is by now widely recognized that to expand the numbers of students choosing scientific and engineering careers, we first need to get them to take the pre-college science and mathematics prerequisites to those career paths. One group which has begun to do something about encouraging pre-college science education is the Optical Society of America. Through its Education Council, OSA has begun a program of education grants for pre-college optics education, an Educator's Day program for science teachers at its annual meeting, an "Optics: A Career spectrum" recruiting brochure, an inexpensive optics kit with an instruction manual, and an educational resources data base which will help prospective optics students learn where they can go to study optics - at both undergraduate and graduate levels.l SPIE has provided an extremely valuable resource to the location of college level programs through its yearly "Optics in Education" brochures.2

The fact that optics, being a highly visual science, can be used effectively to get pre-college (elementary and secondary) students interested in science is something none of us should overlook. The OSA is currently developing marketing plans for its optics kits, which were developed by Dr. Donald C. O'Shea of Georgia Tech and which have been used at the three previous Educator's Days (Washington, D.C. - 1985, Seattle - 1986, Rochester - 1987) to instruct teachers in the use of some basic optics experiments they can use with their students. At each of these Educator's Days (as will be the case at 
Educator's Day 1988 to be held in Santa Clara, CA), on the order of 110-150 selected science teachers from the state or states surrounding the meeting city are hosted for a day of talks and demonstrations on optics. To say that the honored teachers enjoy this experience and are thus more motivated to use optics in their classrooms is to state the obvious. In fact, OSA believes that the "technology" of Educator's Day now needs to be transferred to other professional societies and that if this is done, the potential impact on pre-college education can be enormous.

\subsection{College-level Recruiting}

Once students have enrolled in college (say in physics or engineering, although other curricula are also of interest), we face the problem of interesting them in optics. While many may be vaguely aware of some of the "fruits" of the "optics revolution" (e.g. fiber optic communications, compact disk memories, laser scanners, laser surgery, semiconductor lasers and holography) knowing where they can learn about modern optics is not always easy. Let us examine some of the obvious recruiting vehicles.

\subsubsection{Courses}

Courses are obvious places to interest students in optics. When taught effectively with enthusiasm, optics can be a fascinating subject at almost any level of a B.S. curriculum. The standard places for exposure to optics seem to be introductory physics, and a junior/senior introduction to optics in physics departments and in engineering senior electives on topics such as an overview of optics, fiber optics, optical electronics, lasers, or digital image processing.

What induces students to sign up for an optics course? The possibilities for generating enthusiasm here are endless, but include bulletin board displays from trade magazines, articles on the growing demand/starting salaries in optics-related jobs, profiles of past graduates employed in optics, posters, brochures, etc.

While on the subject of courses, we must note that it is critical, if at all possible, to include some of the recent applications of modern optics in these courses. To illustrate, while some geometrical and physical optics obviously need to be presented in many introductory courses, leaving out current topics such as lasers, fiber optics, Fourier optics, and holography will almost guarantee a "turned off" student and should be avoided whenever possible. While a number of "balanced" texts are available, it is also clear that more need to be written, particularly for engineering students.

\subsubsection{Laboratory Projects}

While many physics and some engineering departments will offer separate optics laboratory courses, optics-related projects in non-specialized laboratory courses such as project-type laboratories can be major factors in interesting students in optics as a field of study. At Texas Tech University, we have found that optics-related projects such as spatial filtering, reflection holograms, fiber sensors and speckle interferometry can get students interested in elective courses in optics. We have developed, under three separate NSF grants, a number of projects in areas such as lasers, optical information processing, and fiber optics.3,4 We have found that these projects worked to help us to recruit both for our senior optics electives and for our M.S./Ph.D. graduate programs. It is clear that similar projects have achieved the same goal at other schools.

\subsubsection{Laboratory Assistant Jobs}

Undergraduate students are frequently employed, on a part-time basis, in graduate research laboratories. As such they get involved in a variety of tasks such as purchasing, construction of experimental apparatus, computer graphics and taking experimental data. Such an exposure to what optics research is all about can be useful both in interesting students in undergraduate optics courses/labs. Faculty often invite some of the best students in their undergraduate classes to work in their labs with the idea of later recruiting them as graduate students. Since today's undergraduates frequently need to earn part or all of their college expenses, this is a very attractive approach to recruiting prospective graduate students.

\subsubsection{Other Approaches}

other effective recruiting ideas at the undergraduate level include research lab open houses, posters, display cases highlighting student trips, publications, etc. Where local optics-related companies are available, field trips can be useful. Those who are fortunate enough to have professional meetings nearby with optics equipment displays can urge their students to attend. Here, the key is to be creative in ways that will con- 
vince prospective students that there are exciting career activities in optics-related companies.

\section{RECRUITING AT THE GRADUATE (M.S./Ph.D) LEVEL}

Though this conference deals primarily with B.S. and M.S. level programs, it should be noted that the availability of a Ph.D. program is a definite asset in recruiting M.S. candidates. Our experience has been that M.S. theses, when required, are excellent preparation for Ph.D. research and provide a natural environment for determining which students should be recruited for Ph.D. work. My personal belief is that if the M.S. is to be a student's final degree, it is a much stronger degree if a thesis is written due to the maturing effects of the thesis research and writing the thesis.

As was noted earlier, undergraduate optics courses and laboratory projects can be effective recruiting tools for M.S./Ph.D. recruiting, as can opportunities to work in an optics research lab as a laboratory assistant or summer undergraduate research participant. Key factors in the student's decision, however, are the availability of financial aid, the perception of career opportunities and the opportunity to work in an active research group. In the sub sections below, we elaborate on these.

\subsection{Availability of Financial Aid}

There is little question that the prospect of financial aid in the form of a research or teaching assistantship can strongly influence a student's decision to attend graduate school. Pointing out to interested seniors that many if not most engineering and science M.S./Ph.D. students receive assistantships or scholarship/fellowship support can be critical in their decision making process. For the best students, the potential availability of support from sources such as SPIE Scholarships, 2 NSF Graduate Fellowships, OSA's Newport Research Awards, l various Department of Defense awards and other corporate awards can be very attractive. The possibility of supplementary awards with additional income from part-time teaching, can be an added incentive, especially for married students.

It should be noted, however, that at many of the top-rated graduate schools, financial considerations dictate that most research assistantships are going to Ph.D. candidates, so that an M.S. candidate may have to scramble for a teaching assistantship or go without financial aid in the hope of getting aid as a Ph. D. candidate after completing the M.S. degree. With this fact in mind, students should be advised to shop around as there are many good graduate programs at non-top 10 schools. This is especially important when one takes into account the fact that job placement for M.S. and Ph.D. graduates is influenced as much or more by the reputation of the particular research group one works with as it is by the overall research reputation of the university. While few entering graduate students understand this issue, it is certainly worth discussing with them.

\subsection{Perception of Career Opportunities}

We regularly point out to our graduating seniors that a graduate degree opens the door to many career opportunities. Especially now, with fewer U.S. citizens pursuing M.S. and Ph.D. degrees in engineering than in many other industrialized countries, this argument needs to be strongly made. Due to the fact that many companies underutilize the technical training of B.S. graduates, students who want to work in the so called "high technology" areas within physics and engineering are well advised to consider at least getting an M.S. degree. Those who desire to open doors to potential careers in research and teaching should strongly consider the possibility of pursuing a Ph.D. degree.

I believe it is especially important to point out to students that their "window of opportunity" to attend graduate school may well close sooner than they anticipate due to factors such as marriage, children, a home mortgage, and the problems of trying to go back to college after being away from it for a while. Any college educator knows of numerous instances of students who pledged themselves to return later for a graduate degree but never did. I regularly point out to our seniors the value of getting all of their formal education while they are as young as possible. Many if not most companies encourage employees to pursue graduate degrees on a part-time basis, and this certainly should be considered as an option for those who are not interested in full time graduate work following the B.S. degree.

\subsection{Opportunity to Work in an Active Research Group}

In response to an informal questionnaire I circulated, a significant number of faculty at other schools noted how displays of their publications and other signs of an active research group stimulated students to consider graduate work in optics. I do not think 
this point can be overstated. My impression is that the prospective graduate students at a particular university know which research groups are active and what it is like to work for "Professor $X . "$ On the other hand, many students arrive at a particular school not knowing what area they will work in, and find out - via the graduate student grapevine which groups are the most attractive. Needless to say, an enthusiastic group of graduate students are probably any professor's most effective recruiters.

One of the things which clearly attracts graduate students is their perception of opportunities for professional development within a research group. To illustrate, do they hear of the graduate students presenting papers at professional meetings? We and others have found that well drilled M.S. students can give excellent papers at meetings and are, in many cases, motivated by the experience to go on for Ph.D. work when they realize they can compete favorably with students from other universities. Both OSA and SPIE are now encouraging graduate student travel to present papers at professional meetings through the use of grants.1,2

In addition, graduate students frequently are asked to present briefings on their work to visiting scientists and program managers from various funding agencies and companies. Needless to say, these experiences are professionally maturing. When they see their M.S. thesis work appear in a paper on which they are listed as first author, they are quick to pick up the sense of being treated as a professional.

Graduate students in an active research group should, and usually do, learn as much from interacting with each other as they do from the faculty. As this happens and they get deeper in their research, they gradually make the transition from a dependent undergraduate to an independent graduate/professional scientist or engineer.

\subsection{Graduate Course Offerings}

We have not said anything to this point about graduate optics courses as a recruiting tool but clearly they have an impact. In electrical engineering departments courses in areas such as Fourier optics/holography, optical information processing/computing, statistical optics, optical electronics, lasers, and quantum electronics can be effective recruiting tools as can courses in digital image processing, machine vision and medical imaging. Physics departments may find quantum mechanics, solid state physics, laser physics, and electromagnetic field theory, among others, to be effective for recruiting. In mechanical engineering, nondestructive testing using optical techniques in an obvious vehicle for stimulating interest. These should not, however, be taken as exhaustive lists of possible graduate courses related to optics.

\subsection{Assorted Issues}

While we have explored a number of recruiting issues, we have yet to address a key question which is how do students find out about where they can go for graduate training in optics? Both SPIE, following after its successful editions of the "Optics in Education" brochure 2 and OSA, based on the work of its Education Council, l have put together data bases of information regarding educational opportunities in optics. Based on these data bases, it is anticipated that prospective B.S. and M.S./Ph.D. level students will have information available as to where they can study optics and what course/research areas are covered at each school. Interested students and/or their teachers should write SPIE and/or OSA headquarters for this information.1, 2

Many departments also have weekly research seminars where graduate students and faculty discuss their research. These can clearly be effective recruiting tools as well as being good for inter-departmental communications. Another possibility is a yearly special seminar for undergraduates where departmental faculty present talks on their current research interests and graduate student openings.

\section{SUMMARY}

It is clear that many of us working in optics today got there by what we would call "accidents" - i.e. we started out on some other career path and ended up in optics. This is at least partly due to the emerging image of optics as a career field. In the future, there are reasons to believe that this will change in the sense that more people will choose optics on purpose due to its increasing visibility. Part of our mission as optical scientists, engineers and educators is to recruit the next generation of "optikers" who will populate the field as it expands (or explodes) into the twenty-first century. While this is a definite challenge, it is certainly an exciting one and will force us to be both creative and flexible as modern optics continues to redefine itself daily. 


\section{ACKNOWLEDGEMENTS}

I would like to express my appreciation to a number of faculty who gave me their candid views through an informal questionnaire. Their replies were very stimulating and I have tried to incorporate them even though I have not referenced them explicitly. I also sincerely appreciate the assistance of Mrs. Pansy Burtis and Albert Lim in preparing the manuscript and overheads.

\section{REFERENCES}

1. For details, contact the Optical Society of America, Executive Office, 1816 Jefferson Place, N.W., Washington, D.C. 20036.

2. For details, contact SPIE, P.O. Box 10, Bellingham, WA 98227-0010.

3. J.F.Walkup, P.F. Williams, and M.A. Gundersen, "Optics at Texas Tech University: Learning by Doing," IEEE Trans. On Education, Vol. E-23, 118 (1980). Special issue on Optics Education.

4. D.L. Nelson and T.F. Krile, "A Set of Fiber Optics Experiments," IEEE Trans. on Education, Vol. E-26, 133 (1983). 